\title{
Environmentally Resistant Mo-Si-B-Based Coatings
}

\author{
J. H. Perepezko ${ }^{1}$ T. A. Sossaman ${ }^{1}$ M. Taylor $^{1}$
}

Submitted: 7 February 2017/in revised form: 12 April 2017/Published online: 19 May 2017

(C) ASM International 2017

\begin{abstract}
High-temperature applications have demonstrated aluminide-coated nickel-base superalloys to be remarkably effective, but are reaching their service limit. Alternate materials such as refractory (e.g., W, Mo) silicide alloys and $\mathrm{SiC}$ composites are being considered to extend high temperature capability, but the silica surfaces on these materials require coatings for enhanced environmental resistance. This can be accomplished with a Mo-Si-Bbased coating that is deposited by a spray deposition of Mo followed by a chemical vapor deposition of $\mathrm{Si}$ and $\mathrm{B}$ by pack cementation to develop an aluminoborosilica surface. Oxidation of the as-deposited $(\mathrm{Si}+\mathrm{B})$-pack coatings proceeds with partial consumption of the initial $\mathrm{MoSi}_{2}$ forming amorphous silica. This Si depletion leads to formation of a B-saturated $\mathrm{Mo}_{5} \mathrm{Si}_{3}\left(\mathrm{~T}_{1}\right)$ phase. Reactions between the Mo and the $\mathrm{B}$ rich phases develop an underlying $\mathrm{Mo}_{5} \mathrm{SiB}_{2}\left(\mathrm{~T}_{2}\right)$ layer. The $\mathrm{T}_{1}$ phase saturated with $\mathrm{B}$ has robust oxidation resistance, and the $\mathrm{Si}$ depletion is prevented by the underlying diffusion barrier $\left(\mathrm{T}_{2}\right)$. Further, due to the natural phase transformation characteristics of the Mo-Si-B system, cracks or scratches to the outer silica and $\mathrm{T}_{1}$ layers can be repaired from the $\mathrm{Si}$ and $\mathrm{B}$ reservoirs of $\mathrm{T}_{2}+\mathrm{MoB}$ layer to yield a self-healing characteristic. Mo-Si-B-based coatings demonstrate robust performance up to at least $1700{ }^{\circ} \mathrm{C}$ not only to the rigors of elevated temperature oxidation, but also to CMAS attack, hot corrosion attack, water vapor and thermal cycling.
\end{abstract}

\footnotetext{
J. H. Perepezko

perepezk@engr.wisc.edu

1 Department of Materials Science and Engineering, University of Wisconsin-Madison, 1509 University Ave., Madison, WI 53706, USA
}

Keywords environmental resistance $\cdot$ high-temperature coatings $\cdot$ oxidation

\section{Introduction}

The continuing drive to attain increased gas turbine alloys and $\mathrm{SiC}$ composites engine performance in terms of output power along with reduced emissions and improved efficiency requires the incorporation of new high-temperature materials with capabilities beyond the limitations of current Ni-base superalloys (Ref 1). Both multiphase Mo- and Nbbase refractory metal alloys and $\mathrm{SiC}$ composites are receiving increased attention since they offer high temperature strength and creep resistance (Ref 2). While the Mo-Si-B alloys have some intrinsic oxidation resistance, the level is insufficient for operational conditions (Ref 3). In order to provide the supplemental environmental resistance, there is a clear trend to rely on coatings that must exhibit a robust and versatile performance so that they can endure a range of aggressive environments without degradation (Ref 4, 5). For example, in a high temperature combustion environment about $10 \%$ is water vapor that attacks pure chromia and silica to form volatile products (Ref 6). Similarly, salt ingestion and fuel impurities such as $\mathrm{S}$ and $\mathrm{V}$ result in hot corrosion and fluxing of surface protective layers and CMAS (calcia, magnesia aluminosilica) attacks thermal barrier coatings (Ref 7). With this variety of aggressive environments, it is a challenge to identify one coating that will provide the required protection.

The use of thermal spray processing has shown utility in a wide range of applications: coatings for wear, thermal or corrosion resistance as well as environmental barriers. These take the form of either single coating layers or as 
graded multilayers (Ref 8 ). The breadth of uses for these methods reflects the processing flexibility of the technology. In addition to the use of thermal spray technologies for direct coating synthesis, they can also provide a valuable capability in developing a precursor coating that is converted subsequently into a final robust coating structure (Ref 9). To demonstrate the method of thermal spraying a precursor material, an example two-step synthesis of the Mo-Si-B coating on a refractory ceramic composite is presented along with the coating performance in several aggressive environments.

\section{Coating and Substrate Preparation}

Recent developments in environmental resistant coatings involve the implementation of a Mo-Si-B-based system for protection at a range of elevated temperatures (800$1500{ }^{\circ} \mathrm{C}$ ) in ambient air. In the initial development on Mobase alloys, a co-deposition of Si and B via pack cementation yielded an aluminoborosilica outer layer. Subsequent treatment by exposure in air at elevated temperature (1300$1450{ }^{\circ} \mathrm{C}$ ) resulted in the final coating structure. For other substrates without Mo such as cermets, $\mathrm{SiC}$ composites and $\mathrm{ZrB}_{2}$-SiC ceramics, the coating is applied with a two-step method: (1) chemical vapor deposition (CVD) of Mo by the decomposition of $\mathrm{Mo}(\mathrm{CO})_{6}$ at $225{ }^{\circ} \mathrm{C}$; and (2) pack cementation, a CVD process, of $\mathrm{Si}$ and B (35 wt.\% Si:1 wt. \% B ratio) under Ar at $1000{ }^{\circ} \mathrm{C}$. Depositing Mo through the decomposition of $\mathrm{Mo}(\mathrm{CO})_{6}$ results in complete surface coverage of the substrate, but the final Mo layer is less than $10 \mu \mathrm{m}$ thick. This limits the total thickness of the oxidation-resistant coating and thus the $\mathrm{Si}$ and $\mathrm{B}$ reservoir size and, ultimately, the level of protection. The slow deposition rate and production of $\mathrm{CO}$ gas (Ref 10) constrain the process to laboratory scale only. Additionally, many passes of the Mo CVD process are required to coat substrates with complex geometries, showing that this method has little opportunity to be scaled up to industrial standards. A possible alternative is to develop a plasma spray method to apply a surface molybdenum layer on an arbitrary substrate (Ref 9). Compared with the Mo deposition by the CVD carbonyl method, plasma spraying of Mo enables thicker coatings on larger and more geometrically complicated samples. This enables the Mo-Si-B coating be applied to a wider range of end uses and to be scaled up beyond laboratory scales. Plasma spraying deposition works by creating an arc jet and accelerating it through a nozzle. This arc is used to heat the material to be deposited on the substrate. This plasma spray method can achieve sufficiently high deposition rates of refractory metals to be industrially relevant while leaving the substrate undamaged (Ref 8).

\section{Spraying Operations}

For substrates without Molybdenum, a layer of Mo was applied via plasma spraying. The surfaces of the samples were first prepared using a grit blast of 120 grit alumina. Next the samples were preheated to $204{ }^{\circ} \mathrm{C}$ in preparation of the thermal spray process. The source of the Mo to be deposited was as-received H. C. Starck Amperit 105 powder: 99.5\% agglomerated and sintered, a particle size range of $18-57 \mu \mathrm{m}$ and a measured density of $2.25 \mathrm{~g} / \mathrm{cm}^{3}$. A Thermach SG-100 gun was used in the single-pass plasma spraying method, and a Fanuc M-16ib robot was employed for controlled and repeatable application. An Ar/ He gas combination was used in the Arc Plasma Spraying process with an argon carrier gas. Table 1 contains additional spraying parameters. The parameters listed in Table 1 represent the optimum conditions for a high coating deposition efficiency, including a low oxide content.

\section{Coating Synthesis and Structure}

Following the plasma spray deposition of a precursor layer of Mo on to Mo-based substrates, subsequent co-depositions of $\mathrm{Si}$ and $\mathrm{B}$ were applied by pack cementation. The coating process is demonstrated schematically in Fig. 1. The pack powder is comprised of both $\mathrm{Si}$ and $\mathrm{B}$ as the deposition source that is effective within a mixture of 35 wt.\% Si:1 wt.\% B to 20 wt.\% Si: 1 wt. $\% \mathrm{~B}, \mathrm{Al}_{2} \mathrm{O}_{3}$ powder filler and a halide activator such as $\mathrm{NaF}$ or $\mathrm{NH}_{4} \mathrm{Cl}$.

The plasma-sprayed samples were then surrounded by the powder on all sides inside of an alumina boat. The boat was placed in an alumina tube furnace that was then sealed and evacuated, in order to remove oxygen from the system. Pack cementation was performed at $1000{ }^{\circ} \mathrm{C}$ under an atmosphere of argon flowing through the system for times

Table 1 Selected process parameters for the plasma spraying of molybdenum

\begin{tabular}{ll}
\hline Parameter & Value \\
\hline Arc current intensity, A & 700 \\
Effective power (calculated), kW & 14.23 \\
Argon flow rate, scfh & 113.6 \\
Helium flow rate, scfh & 39.7 \\
Powder carrier gas flow rate, scfh & 8.2 \\
Powder feed rate, g/min & 10 \\
Spray distance, inches & 4 \\
Scanning step, inches & 0.125 \\
Transverse speed, inches/second & 40 \\
\hline
\end{tabular}


ranging from $90 \mathrm{~min}$ to $50 \mathrm{~h}$. The details of the pack cementation method are outlined elsewhere (Ref 11-13).

Following the pack cementation, a process of conditioning annealing treatments at $1200-1400{ }^{\circ} \mathrm{C}$ for times from 10 to $30 \mathrm{~h}(\operatorname{Ref} 4,14)$ is required to reach the mature coating structure. Indeed, as shown in Fig. 2(a), the B content in the pack powder mixture stabilizes a continuous layer of MoB underneath the silicide layer, between the Mo alloy substrate and the rest of the coating. As illustrated in Fig. 2(b), the nominal composition trajectory for the co-deposition processes can be illustrated by rotation about the nominal substrate composition whereby the vapor source begins as pure $\mathrm{Si}$ before moving to a mixed $\mathrm{Si} / \mathrm{B}$ source.

During oxidation exposures of the $(\mathrm{B}+\mathrm{Si})$-pack alloys, the initial $\mathrm{MoSi}_{2}$ is transformed into the $\mathrm{T}_{1}$ phase as a result of the transient composition trajectory in Fig. 2(b). With continued high-temperature oxidation, the outer $T_{1}$ phase layer eventually will be consumed by dissolution into the substrate. However, the inward flux of $\mathrm{Si}$ and $\mathrm{B}$ that results in the formation of $\mathrm{T}_{1}$ also leads to the growth of the $\mathrm{T}_{2}$ borosilicide and/or boride phase layer. The B/Si ratio of the pack cementation powder source determines the relative amounts of the $\mathrm{T}_{2}$ and $\mathrm{MoB}$ phases below the $\mathrm{T}_{1}$ phase region. This is illustrated

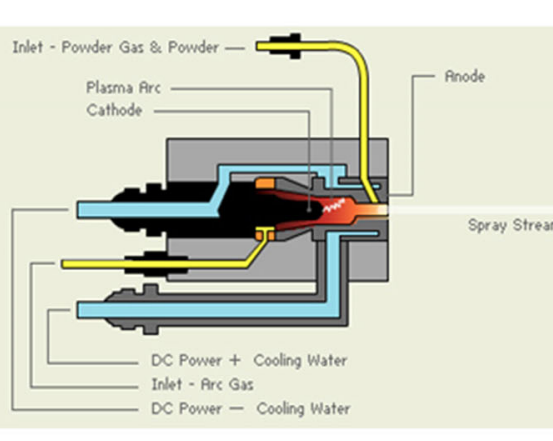

Stage I: PVD of Molybdenum

layer deposition by plasma spray.

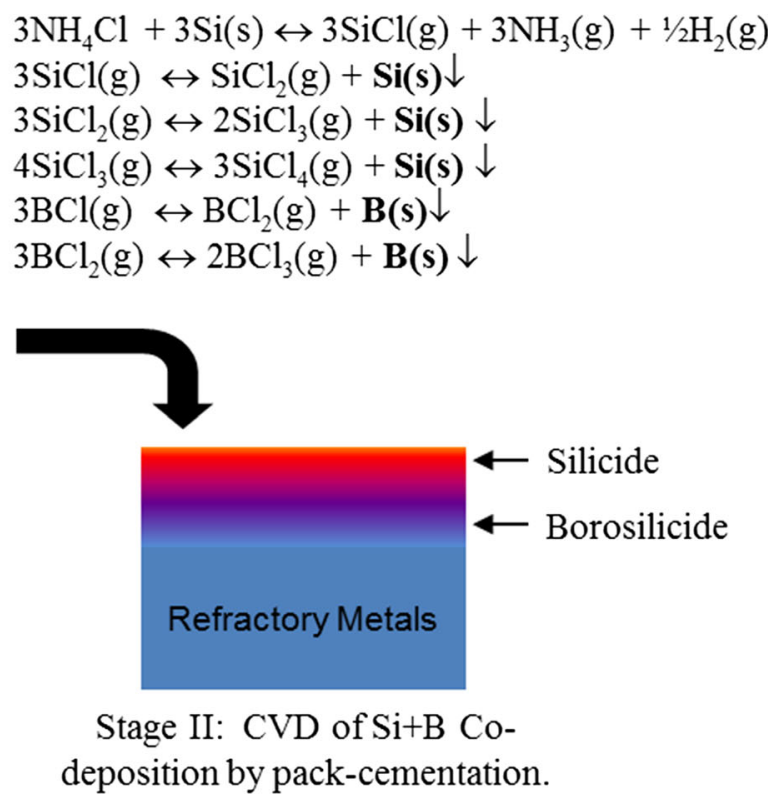

Fig. 1 Schematics of the two-stage coating synthesis method. Stage I is plasma spraying of Mo onto the substrate; Stage II is the CVD process of $\mathrm{Si}$ and B co-deposition (reproduced from Ref 9)

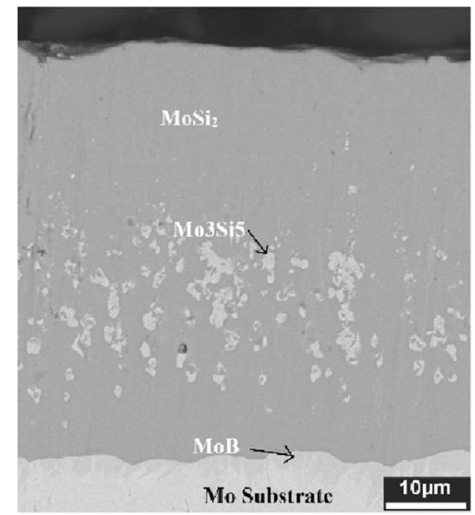

(a)

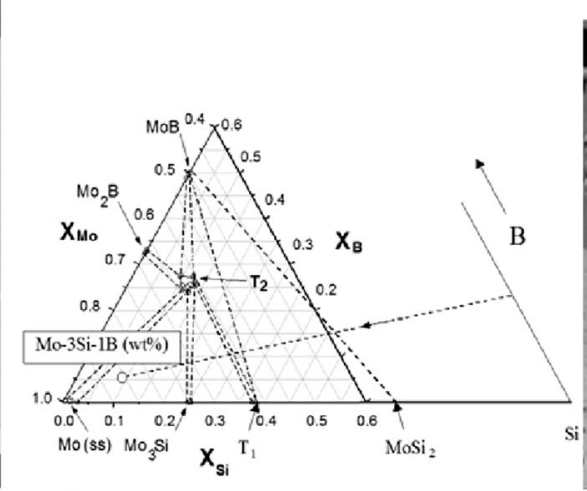

(b)

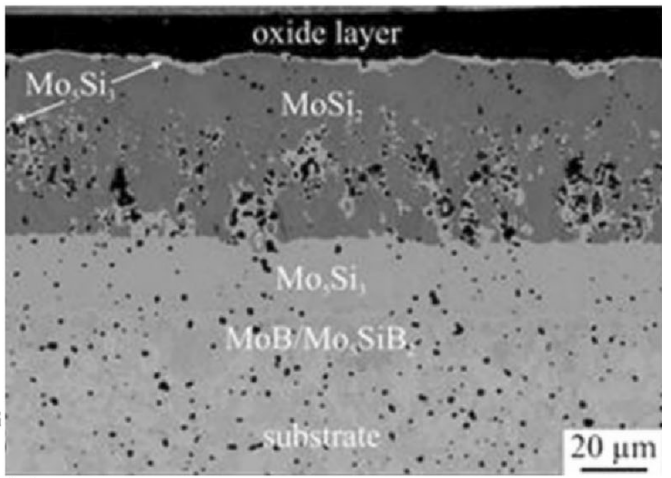

(c)
Fig. 2 (a) As-packed microstructure of Mo-Si-B coating. (b) Composition trajectory of $\mathrm{Si}+\mathrm{B}$ pack cementation process on Mo-3Si-1B (wt.\%) alloys depicted in the Mo-Si-B phase diagram. A full development of the boride phase underneath the silicide phase is observed. (c) Typical post-conditioning microstructure of the Mo-Si-
B coating. An amorphous oxide forms on top of a $\mathrm{MoSi}_{2}$ and $\mathrm{Mo}_{5} \mathrm{Si}_{3}$ two phase region, which in turn covers a layer of $\mathrm{Mo}_{5} \mathrm{Si}_{3}$ and $\mathrm{Mo}_{5} \mathrm{SiB}_{2}$, which acts as a diffusion barrier between the coating and the substrate (Fig. 2(b) is adapted from Ref 4) 
in the composition trajectories presented in Fig. 2(b). Due to the phase equilibria, the $T_{1}$ phase is always in contact with the MoB or $T_{2}$ borosilicide phase, which ensures $B$ saturation in the $\mathrm{T}_{1}$ phase. Furthermore, due to the excellent oxidation resistance of $\mathrm{B}$-saturated $\mathrm{T}_{1}$ (Ref 15,16$)$ the loss of $\mathrm{Si}$ is blocked by the underlying diffusion barrier (i.e., the borosilicide and boride phases). This has the net effect of arresting thickness change of the $\mathrm{T}_{1}$ layer $(\operatorname{Ref} 4,14)$. Further, any damage to the outer $T_{1}$ layer can be repaired from the $\mathrm{T}_{2}+$ MoB layer below. In effect, the same reaction that yields the $\mathrm{T}_{2}+$ MoB layer additionally provides a kinetic bias (Ref 5 ) that allows for the continued existence of the outer $T_{1}$ layer and also results in a self-healing characteristic of the coating.

Oxidation tests performed at $1400{ }^{\circ} \mathrm{C}$ show the effective oxidation protection yielded by the coatings. As shown in Fig. 3(a), with uncoated samples, oxidation of Mo-3Si-1B (wt.\%) alloys causes a large mass loss as shown by the thickness reduction in the samples. The cross-sectional SEM image of the oxide scales shows that although there is a thick and continuous borosilicate layer on the surface, the high evaporation rate of $\mathrm{B}_{2} \mathrm{O}_{3}$ as well as $\mathrm{MoO}_{3}$ at this temperature results in a relatively high recession rate during the transient oxidation. In contrast, the coated sample shows the thickness retention of the sample and furthermore sluggish growth of the borosilicate layer on top of the coating (less than $15 \mu \mathrm{m}$ after 30-h exposure).

\section{Water Vapor Exposure}

Water vapor is known to accelerate oxidation attack in a combustion environment. Silicon containing compounds are thusly attacked due to the formation of volatile silica hydroxides, which rapidly leave the system (Ref 6, 17-20). Previous work on the oxidation of silica by steam in a flowing gas stream has been successfully modeled as paralinear behavior that results in rapid recession of the surface (Ref 6, 17-20). With the addition of boron to the silica, additional hydroxide phases become relevant, some of which are stable, including $\mathrm{BO}(\mathrm{OH}),[\mathrm{BO}(\mathrm{OH})]_{3}$ and $\mathrm{B}(\mathrm{OH})_{3}$ (Ref 17, 21, 22). Boron exposed to wet oxidation has been observed to form volatile boron hydroxides in significant amounts at relatively modest temperatures (Ref 17). However, the effect of wet oxidation on borosilicide coatings, including Mo-Si-B-based coatings, has not been fully evaluated particularly at high temperature $\left(>1400{ }^{\circ} \mathrm{C}\right)$.

Wet oxidation conditions cause uncoated Mo-Si-B alloys to demonstrate major mass losses. This is demonstrated in Fig. 4(a), where an uncoated Mo-Si-B alloy was subjected to wet air at $1400-1500{ }^{\circ} \mathrm{C}$ for $24 \mathrm{~h}$. Steadystate oxidation is eventually reached, in which a borosilica surface layer develops at the rate observed in coated samples, but not before significant mass losses. The volatilization and loss of Mo via Mo oxides and/or Mo hydroxides coupled with a high relative $\mathrm{B} / \mathrm{Si}$ ratio delayed the approach of steady-state oxidation (Ref 8$)$. The coated samples instead have an initial borosilica surface layer as well as the underlying borosilicide phases. Figure 4(b) illustrates that these features protect against aggressive water vapor attack conditions. Moreover, a detailed study of the coating composition has elucidated that the glass contains residual $\mathrm{Al}$ and $\mathrm{Na}$ that was incorporated from the pack powder to form an aluminoborosilica glass (Ref 12).

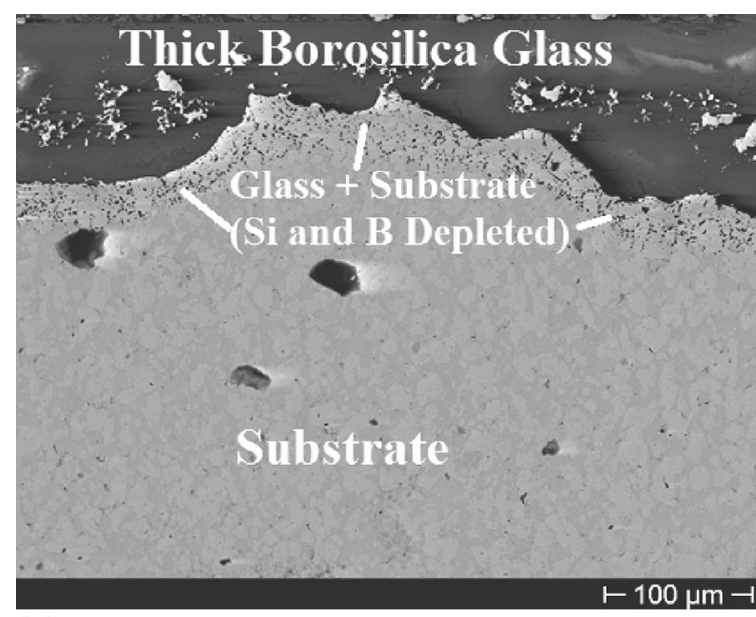

(a)

Fig. 3 (a) Oxidation of an uncoated sample of Mo-3Si-1B (wt.\%) in air at $1400{ }^{\circ} \mathrm{C}$ for $10 \mathrm{~h}$ results in a large mass loss as evident by the thickness reduction in the sample. The SEM cross section of the oxide scales shows that even though there is a thick and continuous borosilica layer on the surface, the high evaporation rate of $\mathrm{B}_{2} \mathrm{O}_{3}$ at

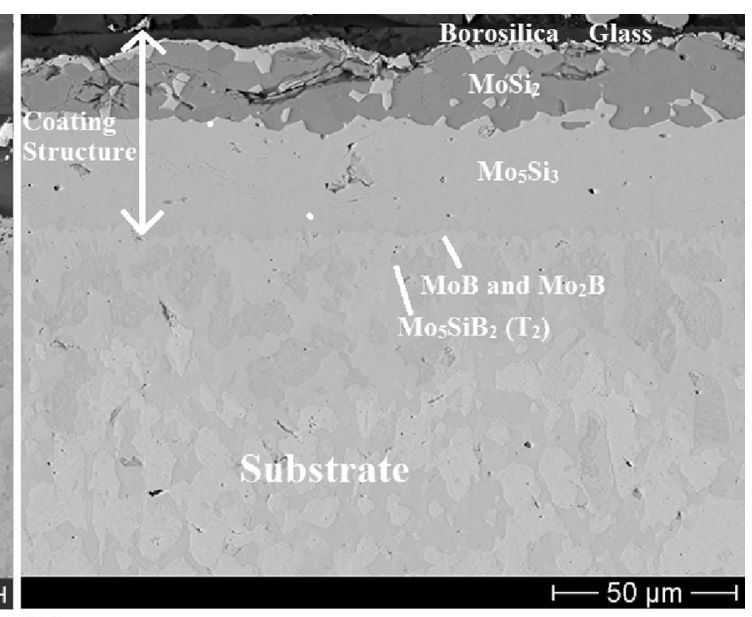

(b)

this temperature results in a relatively large mass loss during the transient oxidation. (b) In contrast, the coated sample subjected to the same exposure in air at $1400{ }^{\circ} \mathrm{C}$ for $10 \mathrm{~h}$ shows thickness retention and very limited growth of the borosilica layer on top of the coating (adapted from Ref 4) 


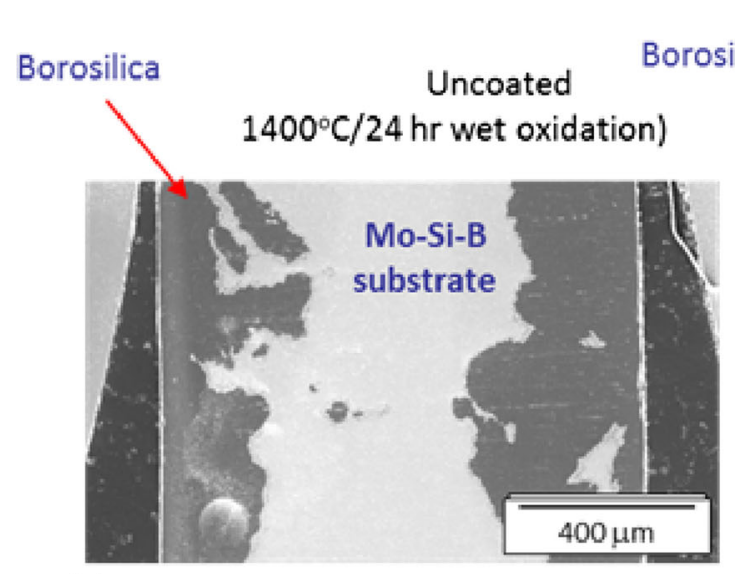

(a)
Borosilicide Coating

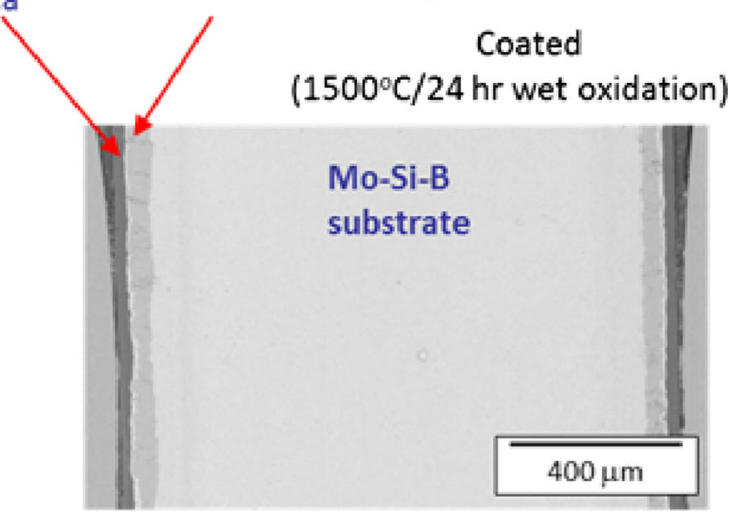

(b)

Fig. 4 SEM cross section of (a) uncoated (b) coated Mo-Si-B coupon exposed to wet oxidation showing the benefit of borosilicide coatings in minimizing the mass recession rate (adapted from Ref 5)

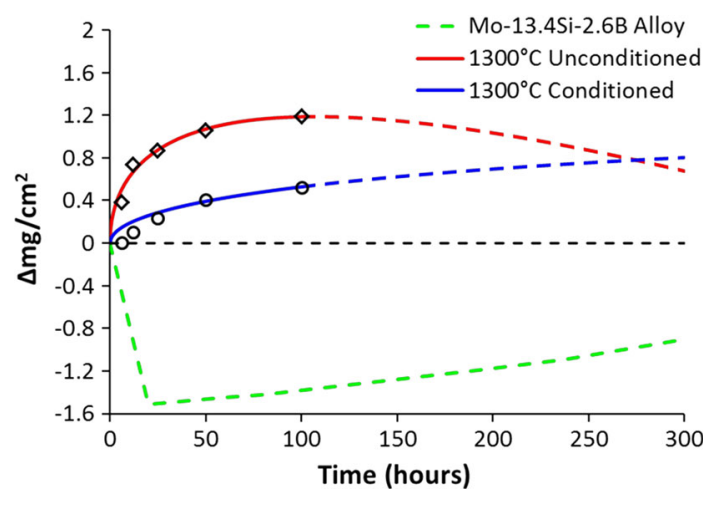

Fig. 5 Experimental data and fitted model for conditioned and unconditioned sample oxidized at $1300{ }^{\circ} \mathrm{C}$ up to $100 \mathrm{~h}$, showing significant improvements in performance vs. uncoated Mo-Si-B alloys and by conditioning

Coating pure Mo with Mo-Si-B probes solely the protective capabilities of the coating, thus removing any influence from intrinsic oxidation resistance of the alloy. The mass change per area plot in Fig. 5 illustrates the coating's protective ability under conditions of water vapor attack at $1300{ }^{\circ} \mathrm{C}$ compared to an uncoated Mo-Si-B alloy in the same conditions at $1100{ }^{\circ} \mathrm{C}(\operatorname{Ref} 23)$. Two sets of coated samples are shown, with conditioned samples being pre-oxidized in ambient air, as earlier outlined, prior to water vapor exposure. Unconditioned samples were instead exposed to water vapor immediately after pack cementation. The alloy exhibits initial mass losses during transientstage oxidation before steady state; both the conditioned and unconditioned Mo-Si-B coatings instead show immediate mass gain and paralinear oxidation kinetics.

Both literature (Ref 23, 24) and the current work suggest that there are two primary factors that result in the minimal effect of water vapor on the high temperature oxidation performance of Mo-Si-B coatings. The water vapor effect on the Mo-Si-B alloys is significant during the transient stage of the oxidation process, causing increased recession rates and mass losses from the evaporating volatiles (both Mo hydroxides and $\mathrm{MoO}_{3}$ ). However, the current work demonstrates that the presence of a preexisting aluminoborosilica scale from the coating reduced the transientstage oxidation considerably and thus water vapor attack is almost completely mitigated. In essence, the preexisting glass lowers the available oxygen partial pressure at the $\mathrm{MoSiB}$ coating/glass interface, sufficiently below the threshold to prevent the formation of either $\mathrm{MoO}_{3}$ or $\mathrm{Mo}$ hydroxide. Rather, solid-state transformation from $\mathrm{Si}$-rich to more Mo-rich silicides for the production of $\mathrm{SiO}_{2}$ is favorable over concurrent $\mathrm{MoO}_{3}(\mathrm{~g})$ or $\mathrm{MoO}_{2}(\mathrm{~s})$ production, which occurs below an oxygen partial pressure of approximately $1.01 \mathrm{~Pa}(\operatorname{Ref} 24)$. This can be ascribed to the continued presence of glass modifiers such as $\mathrm{Al}, \mathrm{Na}$ and $\mathrm{B}$ within the silica. These can be detected even after exposure at temperature as high as $1650{ }^{\circ} \mathrm{C}(\operatorname{Ref} 12,25)$. The current study suggests that the additive retention benefits the coatings by lowering the effective mass loss rate of the silica-based glass.

Another major factor of water vapor attack described in previous studies is the process of accelerated crystallization of silica-based glass. The formation of cristobalite encourages porous structures that cause additional degradation. The current work shows that the glass produced from MoSiB coatings does not exhibit this particular water vapor behavior. However, there is an observable difference in the character of glass produced under water vapor conditions (unconditioned coatings) and of glass produced in ambient air prior to water vapor testing (conditioned coatings). The conditioned coating in Fig. 5 demonstrates a greater capability of resisting both oxidation and hydroxide formation when the initial protective oxide layer is 
established in ambient air, which is noted by the lower net mass gains and the extended timescale for the paralinear behavior of the conditioned sample. It is clear that the development of the continuous borosilica layer in the presence of water vapor alters its protective capabilities. Despite this observation, the glass formed during the water vapor exposures retains an amorphous structure. This is hypothesized to result from the additive retention during oxidation, but further study is required to verify this explanation.

\section{Cyclic Oxidation Performance}

For a complete evaluation of the layered coating structure performance, isothermal exposure is inadequate since the potential mechanical incompatibility due to different coefficients of thermal expansion of the layers can yield cracking and degradation during thermal cycling. The cyclic oxidation exposures were conducted at $1300{ }^{\circ} \mathrm{C}$ in air with a 10-h hold followed by furnace cooling between each cycle. Figure 6 depicts the normalized mass change results during the 500-h of oxidation exposure at $1300{ }^{\circ} \mathrm{C}$. The two samples exposed inside an alumina crucible are represented with filled symbols, whereas the two samples that were placed on alumina-free $\mathrm{SiC}$ foam are shown with empty marks. All four samples exhibited material loss during the first 100 to $120 \mathrm{~h}$ of cycling. After $100 \mathrm{~h}$ of oxidation, one sample of each condition was cut and imaged in the SEM. The remaining two samples were further tested for an additional $400 \mathrm{~h}$ and experienced discontinuous mass gains. Even though the time duration was too short to demonstrate parabolic oxidation kinetics, the overall magnitude of mass change is quite slow for testing at $1300{ }^{\circ} \mathrm{C}$; with a maximum value of $+/-0.2 \mathrm{mg} /$ $\mathrm{cm}^{2}$. An analysis of morphological changes and phase evolution as a result of the exposure can elucidate the cause

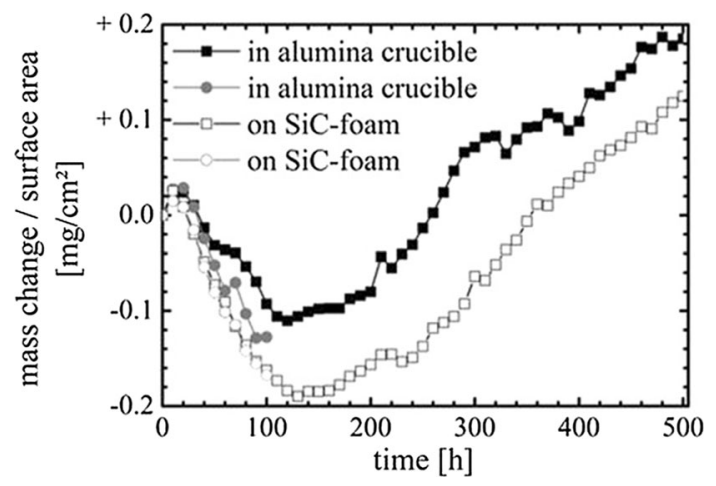

Fig. 6 Cyclic mass change per surface area vs. time of the coated samples at $1300{ }^{\circ} \mathrm{C}$. Note the small overall magnitude of mass change in the 500-h duration exposure (adapted from Ref 42) for the mass loss and deviation from parabolic behavior. The microstructure, mass change and chemical composition exhibited difference between the sample holders, thus, do not have an effect on overall mechanism.

Since the coating structure during $\mathrm{Si}+\mathrm{B}$ pack cementation can be formed regardless of the base Mo alloy composition, the effectiveness of this method was applied to a Mo-rich alloy, TZM (typical TZM has three major alloying elements of 0.4-0.55 wt.\% Ti, 0.06-0.12 wt.\% Zr and 0.01-0.04 wt.\% C). Both Si and B were deposited onto the TZM substrate by pack cementation. It is well known that there is a large coefficient of thermal expansion (CTE) mismatch between $\mathrm{MoSi}_{2}$ and the TZM alloys as illustrated in Fig. 7. Despite superb coating performance under isothermal conditions, this CTE mismatch is cause for concern when applying the coatings in a cyclic environment. In fact, it has been well documented that the disilicide $\left(\mathrm{MoSi}_{2}\right)$ performs quite poorly when subjected to cyclic oxidation tests when is applied onto Mo. Significant mass losses are observed due to $\mathrm{MoO}_{3}$ volatilization. Large residual stress is generated during cooling that lead to cracks that propagate through the coating and cause accelerated degradation. However, as Fig. 7 indicates, in contrast to $\mathrm{MoSi}_{2}$, the CTE of the $a$ axis for the $\mathrm{T}_{1}$ phase is a near match to that of TZM. In fact, it was found that MoSi2 within the coatings could be converted into a [001] textured $\mathrm{T}_{1}$ phase by a simply annealing (i.e., conditioning) the specimens as illustrated by the inverse pole figure on the growth direction as well as the pole figures orthogonal to several crystallographic planes (Fig. 8). The result of replacing the disilicide by the $T_{1}$ phase on the cyclic oxidation resistance of the coatings has been demonstrated to yield an oxidation performance that approaches the excellent behavior observed in isothermal cases. This is partially owed to an absence of transverse cracking in the

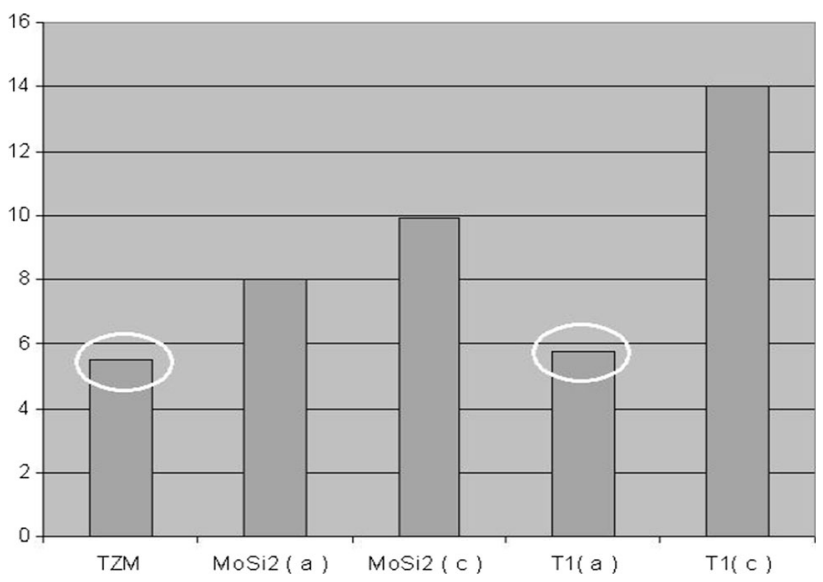

Fig. 7 Coefficent of thermal expansion (CTE) $\left(10^{-6} / \mathrm{K}\right)$ for TZM, MoSi2 (a and c) and $\mathrm{T}_{1}$ phase (c). The CTE values of TZM and $\mathrm{T}_{1}$ phase (a) are almost similar (reproduced from Ref 7) 


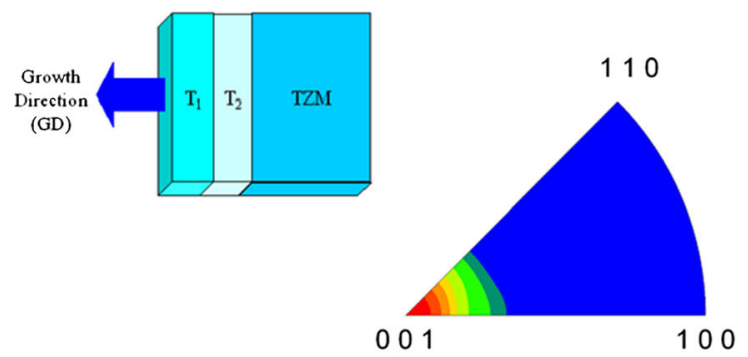

(a)

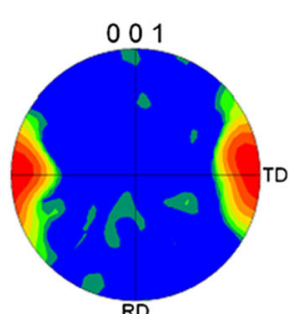

(b)

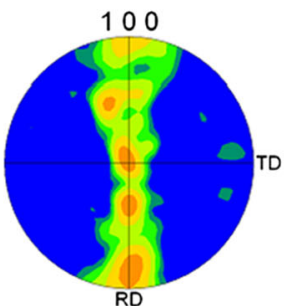

(c)

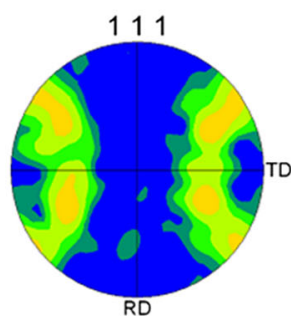

(d)

Fig. 8 (a) Inverse pole figure of the $T_{1}$ phase coatings on the TZM alloys along the growth direction showing the [001] preference, (b)-(d) pole figures along several crystallographic planes confirming the texture (reproduced from Ref 7)

$\mathrm{T}_{1}$ phase due to good CTE matching. Moreover, the coated samples avoid pesting during oxidation at $700{ }^{\circ} \mathrm{C}$ (Ref $4,5)$.

\section{Arc Jet Exposure}

The harsh conditions experienced by spacecraft during atmospheric reentry or aircraft during hypersonic flight result in extremes in temperature $\left(>2000{ }^{\circ} \mathrm{C}\right)$ which require materials with ultra-high melting temperatures. Refractory metals or high melting temperature ceramics are the primary candidates for such challenging applications. Furthermore, because of aerodynamic heating the environment contains hot ionized gases, which cause more aggressive attack than oxidation in static air. In order to simulate these unique conditions, specialized facilities such as arc jet apparatuses are necessary. Most of the literature concerning arc jet testing focus on $\mathrm{HfB}_{2}$ and $\mathrm{ZrB}_{2}$ and their composites with $\mathrm{SiC}$ (Ref 26-29). The primary findings after relatively short exposure times on the order of minutes at temperatures up to $2000{ }^{\circ} \mathrm{C}$ are ablation and erosion of the surface. A near-surface layer zone was observed that extends for $100 \mu \mathrm{m}$ or more where the composite has been altered from the bulk morphology. For longer exposure durations, it is evident that an environment barrier coating is necessary. The Mo-Si-B-based coating was thus evaluated for such an application.

As an initial evaluation of the coating's protective capability to an extreme arc jet environment, the Mo-Si-B coating was applied to pure Mo substrates. After multiple 15- to 20-min arc jet exposures, with temperatures reaching $1600{ }^{\circ} \mathrm{C}$ (see Ref 30 for the details of the arc jet exposure), the samples maintained their morphology, with no significant change in the coating microstructure as shown in Fig. 9(a). To further extend the study, the Mo-Si-B coating was applied to a $\mathrm{ZrB}_{2}-\mathrm{SiC}$ composite by the previously outlined two-step method. Again, after arc jet testing the sample demonstrated good coating adherence as shown in Fig. 9(b). Again, data suggest that the protection provided by the aluminoborosilica surface is related to retention of glass additives (i.e., $\mathrm{Na}, \mathrm{Al}$ and $\mathrm{B}$ ) that act to maintain a non-crystalline surface and a reduced oxygen partial pressure at the substrate/coating interface.

\section{Interaction Between Mo-Si-B Coatings and CMAS}

Thermal barrier coatings are highly developed material systems for increasing the durability and functioning of gas turbine engines ( $\operatorname{Ref} 31,32)$. However, one issue that has received recent attention by several groups is TBC degradation due to ingestion and infiltration of calcia-magnesiaalumino-silicate (CMAS) into the TBC structure (Ref 33, 34). Moreover, thermal barrier coatings are increasingly vulnerable to attack by molten CMAS sand. Thermal barrier coatings (TBCs) made of $\mathrm{ZrO}_{2}$ typically stabilized with 7 wt. $\% \mathrm{Y}_{2} \mathrm{O}_{3}$ are used in gas turbine engines for aircraft engines, power generation and marine applications for higher operating engine temperatures. The molten CMAS attacks the TBC by infiltration into the coating and subsequently results in delamination cracks and damage to the substrate (Ref 35). In addition, the CMAS causes the TBC to exhibit extensive thermomechanical degradation during repeated thermal cycles which leads to a number of delamination mechanisms due to CTE mismatch between the TBC and CMAS. The CTE of TBC is relatively high $\left(9-12 \times 10^{-6} \mathrm{~K}^{-1}\right)$ compared to that of CMAS $(\sim 3-$ $\left.4 \times 10^{-6} \mathrm{~K}^{-1}\right)(\operatorname{Ref} 36,37)$.

Only a few methods for alleviating CMAS attack on YSZ TBCs have been outlined in the literature. One protection method is to employ a sealant or a de-wetting outer layer on the TBC (Ref 31$)$. However, as a result of thermal cycling during operation the outer layer was observed to crack and erode. Another technique is to apply an atmospheric plasma spray (APS) coating (Ref 25). Unfortunately, the morphology of the APS YSZ TBC is typified by the presence of microcracks in the TBC, porosity and "splat" boundaries. Consequently, the interaction between molten CMAS and TBC materials follows the corrosion 


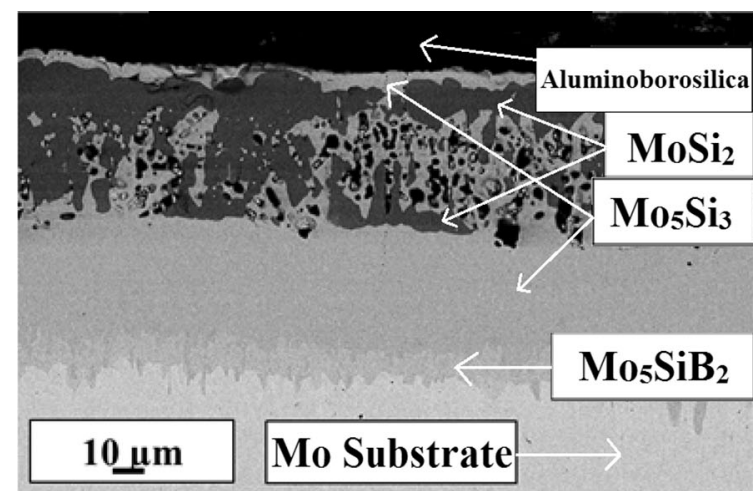

(a)

Fig. 9 (a) SEM micrograph following multiple 15- to 20-min arc jet exposures at temperatures reaching $1600{ }^{\circ} \mathrm{C}$ (see (Ref 31) for the details of the arc jet exposure). The samples maintained their integrity, protecting the oxidation vulnerable Mo substrate. (b) SEM

mechanism noted above. In this current work, the interaction was analyzed between CMAS and MoSiB protective coating. The main idea of the experiment is to create a new type of protective coating as an effective source glass overlays that will interrupt the molten CMAS infiltration into thermal barrier coating by altering the chemical composition and the physical properties of the CMAS.

The MoSiB-based coating was applied to the Mo substrate samples by a pack cementation process where gas phase diffusion of $\mathrm{Si}$ and $\mathrm{B}$ reacts with the Mo surface to convert it into the coating. The pack cementation process was conducted at $1000^{\circ} \mathrm{C}$ for $50 \mathrm{~h}$. Following pack cementation, the surface is converted by conditioning into a mixture of $\mathrm{MoSi}_{2}$ and $\mathrm{MoB}$. After pack cementation processing, the specimens were conditioned for $2 \mathrm{~h}$ at $1600{ }^{\circ} \mathrm{C}$ in ambient air.

In order to establish the interaction behavior of CMAS with the MoSiB-based coating, small quantities (12 mg/ $\mathrm{cm}^{2}$ ) of CMAS powders were sprinkled on the top surface of the coated specimens (Ref 38). A synthetic CMAS paste was produced by a technique which is described by Kramer et al. (Ref 34). The CMAS-covered samples were subjected to oxidation exposure in air at $1200-1500{ }^{\circ} \mathrm{C}$ for $2-, 10$ - and 25-h exposures.

The results shown in Fig. 10 are representative of CMAS exposures. Initial contact of the CMAS with the coating results in the production of $\mathrm{SiO}_{2}$ and a limited amount of $\mathrm{MoO}_{2}$ by the coating. The $\mathrm{MoO}_{2}$ is incorporated into the CMAS to produce $\mathrm{CaMoO}_{4}$ oxide at the surface of the CMAS, as shown in Fig. 10(a). The layered structure after exposure in air these high temperatures is depicted schematically in Fig. 10(c). Upon exposure to Mo-Si-B coatings, the CMAS melts above a particular temperature and through its interaction with the $\mathrm{MoO}_{2}$ generated by the coating becomes depleted in calcium and crystallizes. The

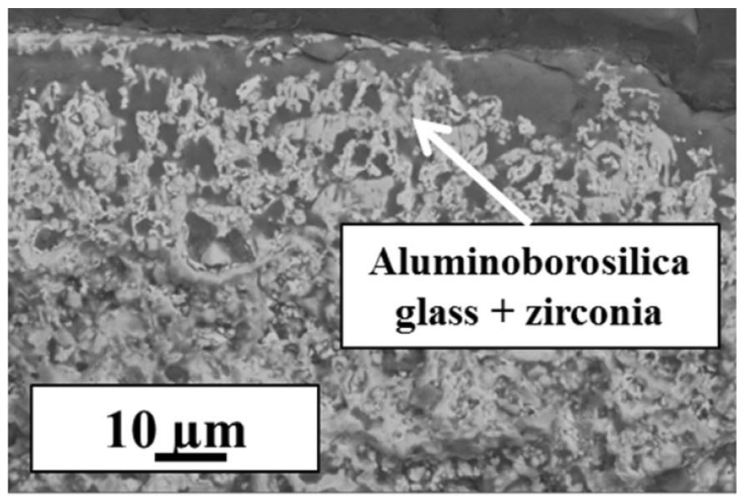

(b)

micrograph of the Mo-Si-B coating applied to a $\mathrm{ZrB} 2-\mathrm{SiC}$ composite after arc jet exposure. The sample exhibits good coating adherence and an unaltered substrate (adapted from Ref 29)

increase in the $\mathrm{Al}$ from the pack cementation process and the $\mathrm{Ca}$ depletion changes the CMAS composition to one that is easy to crystallize. Therefore, this process makes CMAS immobile and inhibits further interaction with the Mo-Si-B coating. This process occurs in addition to the excellent oxidation resistance at high temperatures demonstrated by the Mo-Si-B-based coating when applied to molybdenum alloys and several different substrates.

\section{Hot Corrosion Exposure}

Hot corrosion is a phenomenon primarily encountered in gas turbine engines which operate in salt-containing environments. Salt from sea air can be ingested by an engine and form a stable melt in engine sections which are in the temperature span of $600-900{ }^{\circ} \mathrm{C}$ (Ref 39). Hot corrosion is a form of environmental attack in which a molten salt interacts with a material, causing accelerated corrosive attack. These interactions can lead to irregular and accelerated oxidation behavior. Fused $\mathrm{Na}_{2} \mathrm{SO}_{4}$ considered the dominant salt in hot corrosion can induce a fluxing of a normally protective oxide (Ref 40). Fuel impurities such as $\mathrm{V}$ can also contribute to the final salt scale chemistry. Multiple mechanisms have been put forward to attempt to explain the characteristics of hot corrosion attack, but of interest is the fluxing mechanism (Ref 41). Also of note is the equilibrium between the salt scale and the surrounding vapor environments. This determines the stability of the salt scale, in that still air promotes more stability of the melt, and moving air promotes the decomposition of the salt scale.

To evaluate the susceptibility of Mo-Si-B-based coatings to hot corrosion, the effects of fuel impurities and salt ingestion forming a molten salt scale on the surface of the 


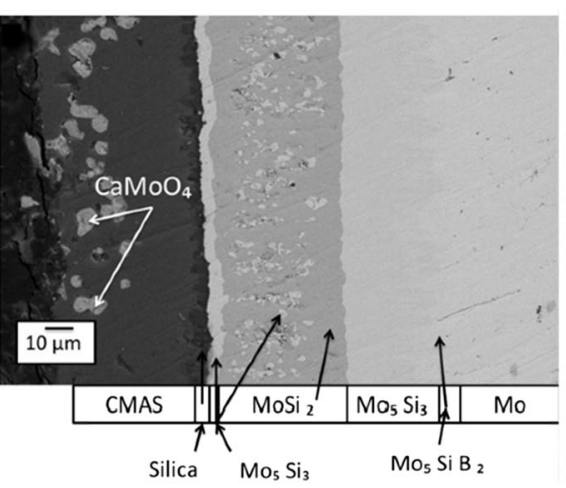

(a)

Fig. 10 (a) Cross-sectional SEM micrograph of MoSiB coating after exposure for $25 \mathrm{~h}$ at $1200{ }^{\circ} \mathrm{C}$ in air, in contact with natural CMAS (Sand A). (b) Plan-view SEM micrograph of top surface of the CMAS

coating must be considered. A solution of a 50/50 mixture by mass of $\mathrm{Na}_{2} \mathrm{SO}_{4}$ and $\mathrm{NaVO}_{3}$ (this mixture was selected because a salt scale containing $\mathrm{V}$ will tend to be acidic due to the acidic nature of $\mathrm{V}_{2} \mathrm{O}_{5}$, which results in the most severe attack (Ref 40,41)) was employed to simulate the worst-case scenario. A slurry of the salt mixture was sprayed onto Mo-Si-B-coated Mo coins, and the solution was dried in a drying cabinet, depositing a film of salt. A Mo substrate was selected due to its lack of inherent oxidation protection at the exposure temperatures, so that only the performance of the coating is demonstrated. Saltcoated coins were then loaded into a furnace for cyclic exposure at 900,1000 and $1300{ }^{\circ} \mathrm{C}$. Due to the projected effect of vapor velocity, tests were carried out in both still and flowing air. Mass and morphology change was tracked between cycles. Finally, the possibility of vapor-phase attack was explored by exposing Mo-Si-B-coated coins without a salt scale, but instead a loose salt charge is loaded into the furnace upstream to expose the sample to salt vapor.

Compiled mass change data are presented in Fig. 11 for cyclic tests at 900 and $1000{ }^{\circ} \mathrm{C}$ for both the still and flowing air cases. Note the survival out to 21, 5-h cycles under flowing air conditions and the general increase in attack severity at higher temperature. Mass losses can be partially attributed to spallation of small fragments of the coating. Associated with this is a visual change in coating character.

The primary effect of hot corrosion attack on the coating is the crystallization of the amorphous silica scale into Cristobalite as demonstrated in the x-ray diffraction (XRD) scans presented in Fig. 12(a) and (b), which demonstrate this fact. Note the diffraction pattern consistent with Cristobalite in Fig. 12(b) replaces amorphous hump observed in Fig. 12(a). This transformation is rapid, as a single 5-h cycle is sufficient to eliminate any amorphous

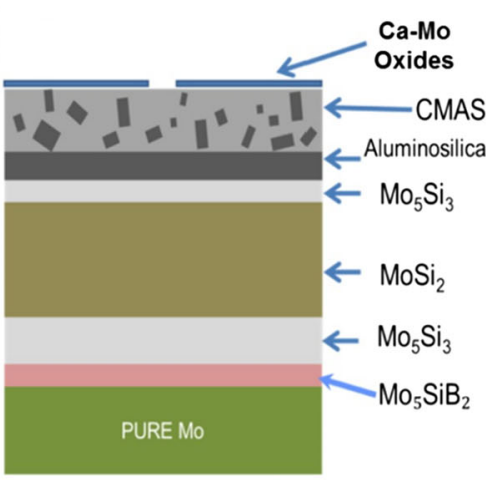

(c)

oxidized for $25 \mathrm{~h}$ at $1400{ }^{\circ} \mathrm{C}$ in air showing the Ca-Mo oxide. (c) Schematic of the coating layer structure depicting the CMAS$\mathrm{MoSiB}$ interactions (adapted from Ref 38)

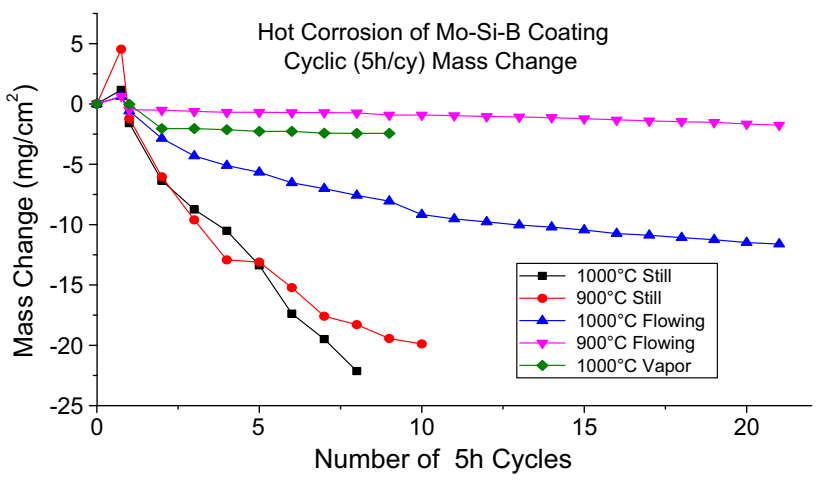

Fig. 11 Compiled mass change data for 900 and $1000{ }^{\circ} \mathrm{C}$, still and flowing air, $50 / 50 \mathrm{Na}_{2} \mathrm{SO}_{4} / \mathrm{NaVO}_{3}$ experiments. The uptick shown before the first cycle is the salt loading applied to the sample. Note the observed survival of a specimen out to 21,5 -h cycles with minimal losses for both the 900 and $1000{ }^{\circ} \mathrm{C}$ flowing air cases

signal. Despite this transformation, the coating retains its protection of the vulnerable Mo substrate. The origin of the continued protection is revealed in the micrograph shown in Fig. 13. The image demonstrates the coating's ability to self-heal and arrest cracks, by forming additional silica at the $\mathrm{MoSi}_{2}$-scale interface, slowing the progression of the oxidation.

Overall, the interaction between the Mo-Si-B coating structure and a molten salt scale results in near-total crystallization of the vitreous silica network. This transformation from silica to cristobalite causes incremental mass losses upon thermal cycling. This growth causes a plainly visible change in coating character. Mass losses are attributed to gradual spallation of the cristobalite, due to a significant volume change upon alpha-beta inversion at $270{ }^{\circ} \mathrm{C}$ (Ref 41 ). It is believed that this crystallization is catalyzed by the $\mathrm{Na}_{2} \mathrm{O}$ groups supplied by the salt facilitating transformation (Ref 41). Attack rates are enhanced when the gas composition is in equilibrium with the liquid 
Fig. 12 (a) XRD scan of MoSi-B coating, pre-exposure. Note the strong amorphous signal at 22 degrees as well as the crystalline $\mathrm{Mo}_{5} \mathrm{Si}_{3}$ and $\mathrm{MoSi}_{2}$ phases present in the scan. (b) XRD scan of Mo-Si-B coating, after $3,5 \mathrm{~h}$ cycles at $1000{ }^{\circ} \mathrm{C}$. Note that the $\mathrm{Mo}_{5} \mathrm{Si}_{3}$ remains but the glassy signal and $\mathrm{MoSi}_{2}$ signatures are absent. This suggests a crystallization of vitreous silica to cristobalite
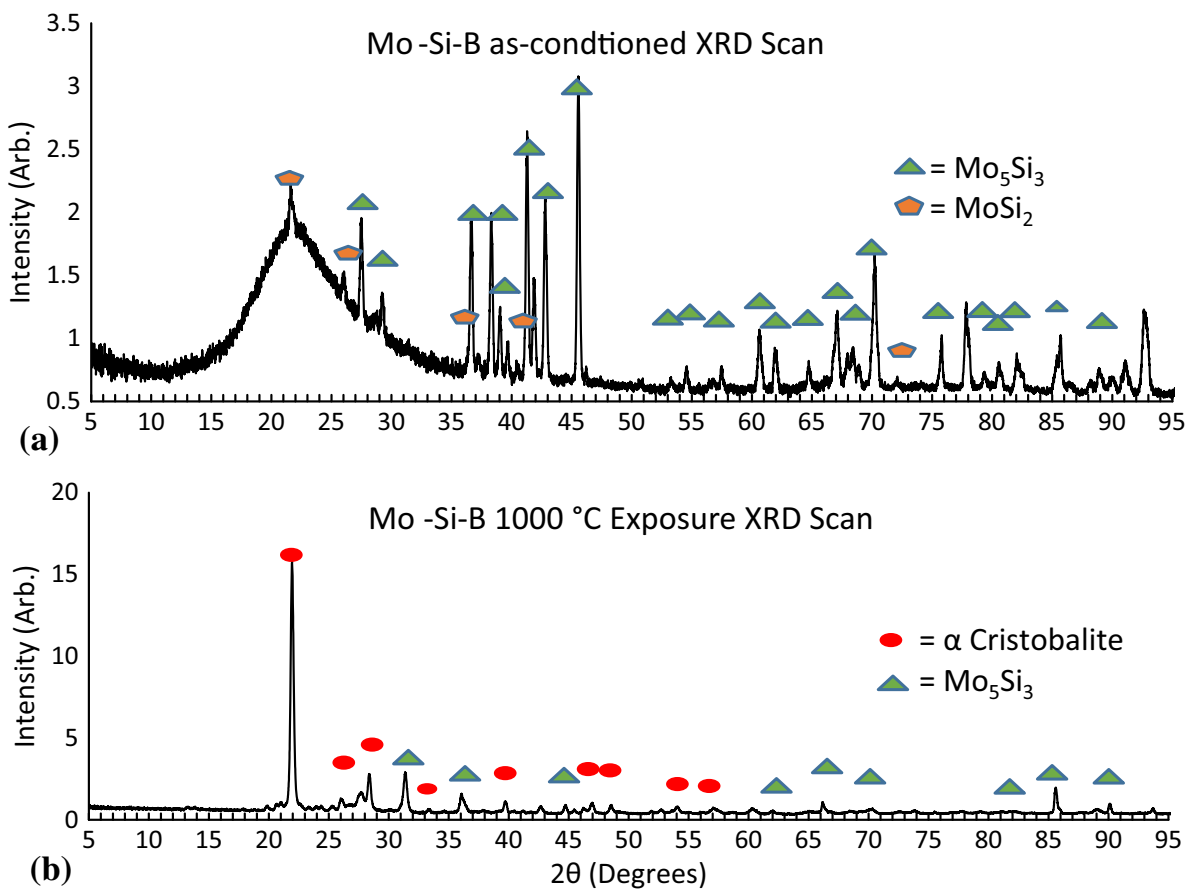

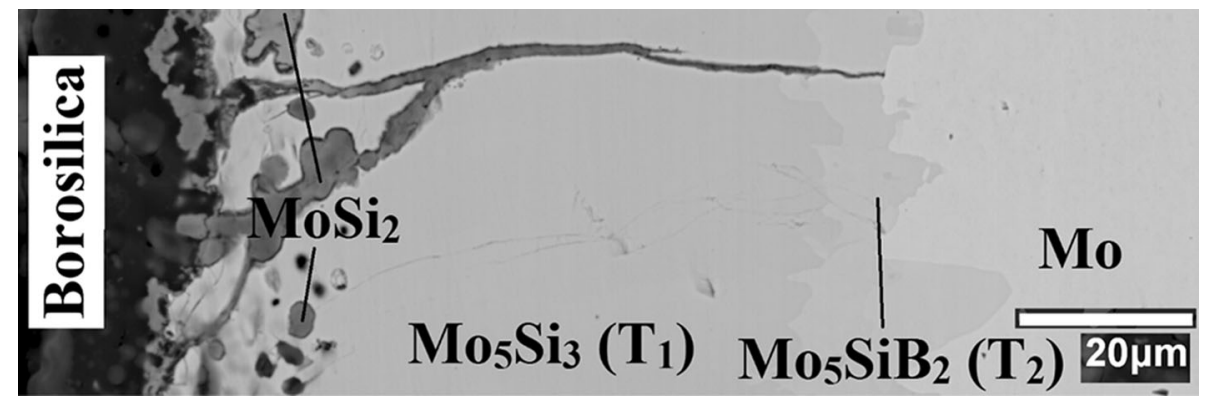

Fig. 13 Secondary electron SEM micrographs of coated specimen subjected to hot corrosion. The specimen was exposed to $215 \mathrm{~h}$ cycles at $900{ }^{\circ} \mathrm{C}$ after loading $4.54 \mathrm{mg} / \mathrm{cm}^{2}$ salt mix. Note that despite cracking the coating has retained its protective ability for the

scale, as this increases the temperature range of stable liquid. However, in the interior of a gas turbine engine such an equilibrium is not expected to be reached.

\section{Conclusions}

The robust natures of the Mo-Si-B-based coating which is effective in limiting oxygen penetration are derived through its ability to self-repair as needed by the regeneration of the outer scale by solid-state transformation of the coating from Si-rich to low-Si-rich phases. This self-regeneration process is especially important under cyclic thermal loading. The coating is highly capable of handling cyclic oxidation, since any cracking of the coating layer during cooling is repaired either through viscous flow of existing coating at sufficiently vulnerable Mo substrate. New $\mathrm{SiO}_{2}$ formation acts to fill in the crack and acts as a self-healing mechanism. Furthermore, note that the cracks terminate at the $\mathrm{Mo}_{5} \mathrm{SiB}_{2}\left(\mathrm{~T}_{2}\right)$ phase and do not continue into the substrate

elevated temperatures, or through regenerative local production of additional borosilica. The $\mathrm{T}_{1}$ and $\mathrm{T}_{2}$ layers play a key role in the termination of crack propagation before it reaches the substrate, which would offer no self-protection and lead to catastrophic failure. The rapid generation of fresh borosilica at the crack walls serves not only to protect the coating from further oxidation, but also to provide an effective barrier to the CMAS and hot corrosion attack, preventing direct access to the coating or underlying substrate interface.

The use of plasma spraying of Molybdenum as the first step in the two-step Mo-Si-B coating method is effective in protecting different substrates such as $\mathrm{SiC}$ composites, $\mathrm{ZrB}_{2}-\mathrm{SiC}, \mathrm{Nb}$ alloys and cermets from oxidation. By using plasma spraying to deposit Mo followed by a co-pack cementation of $\mathrm{Si}$ and $\mathrm{B}$, the Mo-Si-B-based coating can be 
applied to provide enhanced oxidation protection to a wide range of substrates. This provides a proof-of-concept that the plasma spraying of Mo is an effective first step in generation of an oxidation-resistant Mo-Si-B-based coating. Plasma spraying the molybdenum enables the coating of larger and more complicated samples compared to the alternative carbonyl deposition method.

Acknowledgements The support from the Office of Naval Research (N00014-10-1-0913 and N00014-17-1-2575, Dr. David A. Shifler (program manager)) is most gratefully acknowledged. The continued interest and encouragement from Dr. Steven G. Fishman is appreciated.

\section{References}

1. D.M. Dimiduk and J.H. Perepezko, Mo-Si-B Alloys: Developing a Revolutionary Turbine-Engine Material, MRS Bull., 2003, 28(9), p 639-645

2. J.H. Perepezko, The Hotter The Engine, The Better, Science, 2009, 326, p 1068-1069

3. J.A. Lemberg and R.O. Ritchie, Mo-Si-B Alloys for UltrahighTemperature Structural Applications, Adv. Mater., 2012, 24(26), p 1-36

4. J.H. Perepezko and R. Sakidja, Oxidation Resistant Coatings for Ultra-High Temperature Refractory Mo-Base Alloys, Adv. Eng. Mater., 2009, 11, p 892-897

5. J.H. Perepezko and R. Sakidja, Extended Functionality of Environmentally-Resistant Mo-Si-B-Based Coatings, JOM, 2013, 65, p 307-317

6. E.J. Opila, N.S. Jacobson, D.L. Myers, and E.H. Copland, Predicting Oxide Stability in High-Temperature Water Vapor, JOM, 2006, 58(1), p 22-28

7. J.H. Perepezko, Surface Engineering of Mo-Base Alloys for Elevated Temperature Environmental Resistance, Аnпи. Rev. Mater. Res., 2015, 45, p 519-542

8. I. Spitsberg and J. Steibel, Thermal and Environmental Barrier Coatings for $\mathrm{SiC} / \mathrm{SiC} \mathrm{CMCs}$ in Aircraft Engine Applications, Int. J. Appl. Ceram. Technol., 2004, 1(4), p 291-301

9. P. Ritt, O.J. Lu-Steffes, R. Sakidja, J.H. Perepezko, W. Lenling, D. Crawmer, and J. Beske, Application of Plasma Spraying as a Precursor in the Synthesis of Oxidation-Resistant Coatings, $J$. Thermal Spray Tech., 2013, 22(6), p 992-1001

10. J.L. Sabourin and R.A. Yetter, High-Temperature Heterogeneous Reaction Kinetics of Tungsten Oxidation by $\mathrm{CO}(2), \mathrm{CO}$, and O(2), J. Propuls. Power, 2009, 25(2), p 490-498

11. J.H. Perepezko and R. Sakidja, Oxidation-Resistant Coatings for Ultra-High-Temperature Refractory Mo-Based Alloys, JOM, 2010, 62(10), p 13-19

12. P. Ritt, R. Sakidja, and J.H. Perepezko, Mo-Si-B Based Coating for Oxidation Protection of SiC-C Composites, Surf. Coat. Technol., 2012, 206(19-20), p 4166-4172

13. V.A. Ravi, S.D. Cramer, and B.S. Covino, Jr., Pack cementation coatings, ASM Handbook, Volume 13A: Corrosion: Fundamentals, Testing, and Protection, S.D. Cramer, and B.S. Covino, Jr., Eds., ASM International, Materials Park, 2003, p 763-771

14. R. Sakidja, F. Rioult, J. Werner, and J.H. Perepezko, Aluminum Pack Cementation of Mo-Si-B Alloys, Scr. Mater., 2006, 55, p 903

15. M. Akinc, M.K. Meyer, M.J. Kramer, A.J. Thom, J.J. Huebsch, and B. Cook, Mater. Sci. Eng., 1999, 261, p 16

16. M.K. Meyer, A.J. Thom, and M. Akinc, Oxide Scale Formation and Isothermal Oxidation Behavior of Mo-Si-B Intermetallics at 600-1000 ${ }^{\circ} \mathrm{C}$, Intermetallics, 1999, 7, p 153
17. N.S. Jacobson, D.L. Myers, E.J. Opila, and E.H. Copland, Interactions of Water Vapor with Oxides at Elevated Temperatures, J. Phys. Chem. Solids, 2005, 66, p 471-478

18. E.J. Opila, Oxidation and Volatilization of Silica Formers in Water Vapor, J. Am. Ceram. Soc., 2003, 86, p 1238-1248

19. E.J. Opila, Paralinear Oxidation of CVD SiC in Water Vapor, $J$. Am. Ceram. Soc., 1997, 80, p 197-205

20. E.J. Opila, Paralinear Oxidation of Silicon Nitride in a WaterVapor/Oxygen Environment, J. Am. Ceram. Soc., 2003, 86, p 1256-1261

21. F. Rebillat, X. Martin, E. Garitte, and A. Guette, Design, Development, and Applications of Engineering Ceramics and Composites, Am. Ceram. Soc., 2010, 215, p 151-166

22. K. Gente, F. Rebillat, and F. Langlais, High Temperature Corrosion and Materials Chemistry III: Proceedings of the International Symposium, Pennington NJ Electrochemical Society, 2003, pp. 545-556.

23. P. Mandal, A.J. Thom, M.J. Kramer, V. Behrani, and M. Akinc, Mater. Sci. Eng. A, 2004, 371, p 335-342

24. F.A. Rioult, S.D. Imhoff, R. Sakidja, and J.H. Perepezko, Transient Oxidation of Mo-Si-B Alloys: Effect of the Microstructure Size Scale, Acta Mater., 2009, 57, p 4600-4613

25. J.M. Drexler, K. Shinoda, A.L. Ortiz, D.S. Li, A.L. Vasiliev, A.D Gledhill, S. Sampath, and N.P. Padture, Air-Plasma-Sprayed Thermal Barrier Coatings that are Resistant to High-Temperature Attack by Glassy Deposits, Acta Mater., 2010, 58, p 6835-6844

26. T.A. Jackson, D.R. Eklund, and A.J. Fink, High Speed Propulsion: Performance Advantage of Advanced Materials, J. Mater. Sci., 2004, 39, p 5905

27. W.G. Fahrenholtz and G.E. Hilmas, Oxidation of Ultra-High Temperature Transition Metal Diboride Ceramics, Int. Mater. Rev., 2012, 57, p 61

28. M.M. Opeka, I.G. Talmy, and J.A. Zaykoski, Oxidation-Based Materials Selection for $2000 \mathrm{C}+$ Hypersonic Aerosurfaces: Theoretical Considerations and Historical Experience, J. Mater. Sci., 2004, 39, p 5887

29. E. Eakins, D.D. Jayaseelan, and W.E. Lee, Toward OxidationResistant ZrB2-SiC Ultra High Temperature Ceramics, Metall. Mater. Trans. A, 2011, 42A, p 878

30. P.J. Ritt, P.A. Williams, S.C. Splinter, and J.H. Perepezko, Arc Jet Testing and Evaluation of Mo-Si-B Coated Mo and SiC-ZrB2 Ceramics, J. Eur. Ceram. Soc., 2013, 34(15), p 3521-3533

31. N.P. Padture, M. Gell, and E.H. Jordan, Thermal Barrier Coatings for Gas-Turbine Engine Applications, Science, 2002, 296, p 280284

32. R.C. Reed, Superalloys and Coatings for High-Temperature Applications, JOM, 2006, 58, p 36

33. X. Chen, Calcium-Magnesium-Alumina-Silicate (CMAS) Delamination Mechanisms in EB-PVD Thermal Barrier Coatings, Surf. Coat. Technol., 2006, 200, p 3418-3427

34. S. Kramer, J. Yang, C.G. Levi, and C.A. Johnson, Thermochemical Interaction of Thermal Barrier Coatings with Molten CaO-MgO-Al2O3-SiO2 (CMAS) Deposits, J. Am. Ceram. Soc., 2006, 89, p 3167-3175

35. B.J. Harder, J. Ramirez-Rico, J.D. Almer, K.N. Lee, and K.T. Faber, Chemical and Mechanical Consequences of Environmental Barrier Coating Exposure to Calcium-Magnesium-Aluminosilicate, J. Am. Ceram. Soc., 2011, 94, p S178-S185

36. A.G. Evans and J.W. Hutchinson, The Mechanics of Coating Delamination in Thermal Gradients, Surf. Coat. Technol., 2007, 201, p 7905-7916

37. S. Kramer, S. Faulhaber, M. Chambers, D.R. Clarke, C.G. Levi, J.W. Hutchinson, and A.G. Evans, Mechanisms of Cracking and Delamination Within Thick Thermal Barrier Systems in AeroEngines Subject to Calcium-Magnesium-Alumino-Silicate (CMAS) Penetration, Mater. Sci. Eng. A, 2008, 490, p 26-35 
38. I.P. Downs, J.H. Perepezko, R. Sakidja, and S.R. Choi, Suppressing CMAS Attack with a MoSiB-Based Coating, Surf. Coat. Technol., 2014, 239, p 138-146

39. R.A. Rapp, Hot Corrosion of Materials: A Fluxing Mechanism?, Corros. Sci., 2002, 44(2), p 209-221

40. N. Eliaz, G. Shemesh, and R.M. Latanision, Hot Corrosion in Gas Turbine Components, Eng. Fail. Anal., 2002, 9(1), p 31-43
41. M.G. Lawson, H.R. Kim, F.S. Pettit, and J.R. Blachere, Hot Corrosion of Silica, J. Am. Ceram. Soc., 1990, 73(4), p 989995

42. A. Lange, M. Heilmaier, T. Sossamann, and J.H. Perepezko, Oxidation Behavior of Pack-Cemented Si-B Oxidation Protection Coatings for Mo-Si-B Alloys at $1300{ }^{\circ} \mathrm{C}$, Surf. Coat. Technol., 2015, 266, p 57-63 